\title{
The role of brevican in glioma: promoting tumor cell motility in vitro and in vivo
}

\author{
Renquan Lư ${ }^{1,2}$, Chengsheng Wu', Lin Guo ${ }^{2}$, Yingchao Liư ${ }^{3}$, Wei Mo ${ }^{1}$, Huijie Wang ${ }^{4}$, Jianbo Ding ${ }^{5}$, Eric T Wong ${ }^{6}$ \\ and Min $\mathrm{Yu}^{1 *}$
}

\begin{abstract}
Background: Malignant glioma is a common primary tumor of the central nervous system. Brevican, an abundant extracellular matrix component in the adult brain, plays a critical role in the process of glioma. The mechanisms for the highly invasive behavior of gliomas are still poorly understood. The aim of this study was to examine whether brevican is a predictor of glioma and its roles in glioma cell motility.

Methods: In this study, immunohistochemistry staining for brevican expression was performed in malignant gliomas and benign controls. We also explored the effects of brevican on cell adhesion and migration in brevican-overexpressed cells. Knockdown of brevican expression was achieved by stable transfection of U251 cells transduced with a construct encoding a short hairpin DNA directed against the brevican gene, which correspondingly, down-regulated the proliferation, invasion and spread of brevican-expressing cells. Moreover, the role of brevican in the growth and progression of glioma was demonstrated by in vivo studies.

Results: Our results provide evidence for the molecular and cellular mechanisms that may underlie the motility-promoting role of brevican in the progression of glioma. The role of brevican as a target for immunotherapy might be taken into consideration in future studies.

Conclusions: This study suggests that expression of brevican is associated with glioma cell adhesion, motility and tumor growth, and also is related to glioma cell differentiation, therefore it may be a marker for malignance degree of glioma
\end{abstract}

Keywords: Brevican, Glioma, Astrocytoma, Motility, Tumorigenicity

\section{Background}

Malignant glioma, the most common primary tumor in the central nervous system (CNS) with an almost invariably rapid and lethal outcome, is characterized by a distinctive ability to invade the surrounding tissue [1]. Tumor cell invasion is a particular problem at the time of recurrence after the failure of anti-angiogenesis treatment, resulting in neurological deficits and eventual patient demise [2,3]. Yet, at this time, no drug treatment is available that can interfere with the invasiveness of malignant gliomas.

Brevican is one of the most abundant proteoglycans (PGs) in the postnatal brain and is the smallest core

\footnotetext{
* Correspondence: minyu@shmu.edu.cn

'Department of Biochemistry and Molecular Biology and the Key Laboratory of Molecular Medicine, Ministry of Education, Shanghai 200032, China Full list of author information is available at the end of the article
}

protein among the lectican family [4-6]; its gene is located on chromosome 1q31 and includes 14 exons [7]. Recent studies have shown that brevican expression is restricted within the CNS, including the brain and spinal cord, but is absent in extracranial organs, such as the heart, muscle, liver, kidney, lung, thymus and spleen [8]. Interesting, malignant gliomas exhibit unique brevican isoforms, and brevican is critical for its proinvasive role in glioma [9].

Brevican expression is induced in intracranial grafts of invasive glioma cell lines [10]. Evidence has shown that the coding sequence of the brevican gene in glioma is the same as the brevican gene found in the cortex of the normal brain. Therefore, the regulation of expression of brevican in glioma is not caused by mutation [7]. To date, our understanding of the regulatory mechanisms of brevican functions and the involvement of PGs in cancer

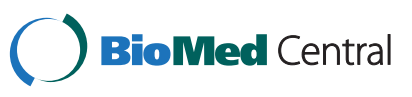

(c) 2012 Lu et al.; licensee BioMed Central Ltd. This is an Open Access article distributed under the terms of the Creative Commons Attribution License (http://creativecommons.org/licenses/by/2.0), which permits unrestricted use, distribution, and reproduction in any medium, provided the original work is properly cited. 
is limited. In our previous mass spectrometry screening in the cerebrospinal fluid (CSF), we found brevican was overexpressed in glioma patients. In this paper, the implication of brevican in cancer development and progression is discussed. Our results demonstrated a motogenic role for brevican and suggested that brevican was a key enhancing factor in the progression of glioma. Targeting brevican might offer a novel and promising approach to cancer immunotherapy by engaging the tumor microenvironment.

\section{Methods}

\section{Tumor tissues of glioma and the control group}

Formalin-fixed paraffin-embedded tissues from 60 patients with glioma of the astrocytoma cell types (grades I, II, III and IV, $n=15$ for each) and 40 patients with non-glioma CNS tumors, including meningioma $(n=20)$ and pituitary adenoma $(n=20)$, were used in this study. All subjects (53 male, 47 female; aged 13-68 years) were retrieved from the archived cases at the Department of Pathology, Fudan University, Shanghai Medical School (Shanghai, China). The clinicopathological characteristics of the 60 glioma patients are shown in Table 1. All of these patients gave their informed consent for this research. This study was approved by the Institute Research Committee at Fudan University, Shanghai Medical School.

\section{Cell lines}

The human glioma U251MG and U87 cell lines, and the non-glioma cell line $293 \mathrm{~T}$ were obtained from the American Type Culture Collection (Manassas, VA). The cells were grown in DMEM medium (Invitrogen, Grand

Table 1 The characteristics of 60 patients with malignant glioma

\begin{tabular}{lc}
\hline Characteristics & $\begin{array}{c}\text { Number of } \\
\text { patients } \\
\text { (N = 60; \%) }\end{array}$ \\
\hline Age (years) & $32(53.3)$ \\
\hline$\leq 50$ & $28(46.7)$ \\
\hline$>50$ & \\
\hline Gender & $30(50.0)$ \\
\hline Male & $30(50.0)$ \\
\hline Female & $15(25.0)$ \\
\hline Histological grade & $15(25.0)$ \\
\hline I & $15(25.0)$ \\
\hline II & $15(25.0)$ \\
\hline III & \\
\hline IV & $30(50.0)$ \\
\hline Degree of differentiation & $30(50.0)$ \\
\hline Well (hair cell type-, oligodendrocyte type- astrocytoma) \\
\hline Poorly (anaplastic astrocytoma, glioblastoma) & \\
\hline
\end{tabular}

Island, NY) supplemented with $10 \%$ fetal bovine serum, 50 units $/ \mathrm{mL}$ penicillin, and $50 \mu \mathrm{g} / \mathrm{mL}$ streptomycin in a humidified atmosphere with $5 \% \mathrm{CO}_{2}$ at $37^{\circ} \mathrm{C}$.

\section{Construction of recombinant plasmids and production of anti-brevican antibodies}

The pIRES-hrGFP-brevican plasmid containing the full sequence of brevican was provided by a Department of Neurology laboratory at the Beth Israel Deaconess Medical Center. The brevican fragment was subcloned into the pMX-puro(+) vector (Invitrogen) to yield pMX-brevican, which was then transfected into 293T, U251 and U87 cells using Fusion $6^{\circledR}$ (Roche, Mannheim, Germany). In addition, the DNA sequence for the N-terminal domain (aa 22-104) of brevican was amplified using the primers 5'-ACGGATCCGCAGATGTTCTG GAAGGAGACA-3' (P1) and 5'-CCGCTCGAGGTAGG CCTCGTTCACCTTGAC- 3' (P2). The brevican N-terminus was also subcloned into the PGEX-4T-1 expression vector (Invitrogen), and brevican recombinant protein was obtained successfully. The anti-brevican antibody B5 was obtained using immunized New Zealand rabbits, performed as previously described [11].

\section{Immunohistochemical (IHC) staining}

The paraffin sections were dewaxed and hydrated, followed by antigen repairing for $20 \mathrm{~min}$. Rabbit antibrevican antibody (B5) was then added at $4^{\circ} \mathrm{C}$ overnight, and horseradish peroxidase labeled anti-rabbit IgG at $37^{\circ} \mathrm{C}$ was incubated for $1 \mathrm{~h}$. Then $0.05 \%$ DAB was added for $5 \mathrm{~min}$, hematoxylin for $1 \mathrm{~min}$, and eosin for $2 \mathrm{~min}$. The IHC sections were stained by hematoxylin and eosin (HE), and scanned under microscopy. The positive index (PI) was calculated using the following formulation: $P I=i \times p$, where $i$ is intensity of staining ( 0 for negative, blue; 1 for weakly-positive, light yellow; 2 for medium positive, yellow; 3 for strong positive, brown), and $p$ is positive percentage of staining ( 1 for $\leq 10 \%$; 2 for 11\%-50\%; 3 for $51 \%-75 \%$; 4 for $>75 \%$ ) [12]. The PI of glioma specimens was compared with that of the control tumors.

\section{Brevican knockdown}

Knockdown of brevican expression was achieved using recombinant plasmids containing short hairpin DNA (shDNA), which were constructed by cloning the respective shDNA into the pSuper-puro vector (Invitrogen). The candidate sequences of the shDNAs were as follows: shDNA 1, 5'GATCCCCGGTGAACGAGGCCT ACCGGTTCAAGAGACCGGTAGGCCTC GTTCACC TTTTTGGAAA3', shDNA 2, 5'GATCCCCGTTATGCT GAAGACCTAAATTC AAGAGATTTAGGTCTTCAG CATAACTTTTTGGAAA3', shDNA 3, 5'GATCCCCG GAG GAAGAAGAGAAATATTTCAAGAGAATATTT CTCTTCTTCCTCCTTTTTGGAAA3'. A mock plasmid 
A
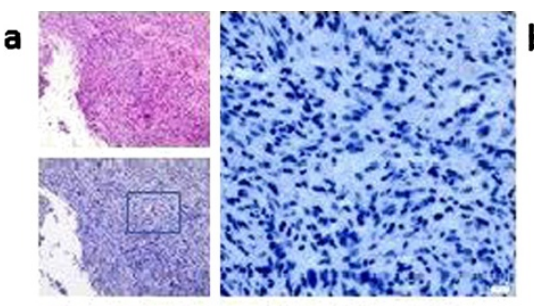

C

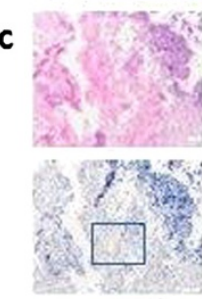

$\mathbf{e}$

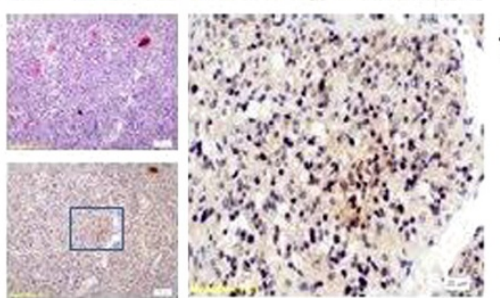

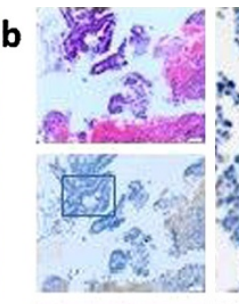

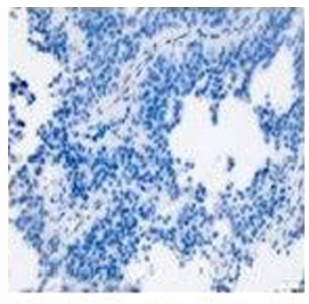

d
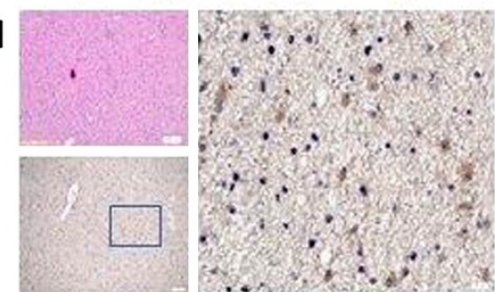

f

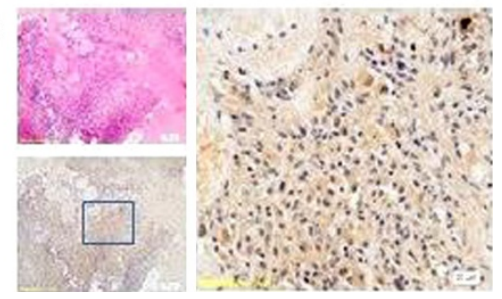

B

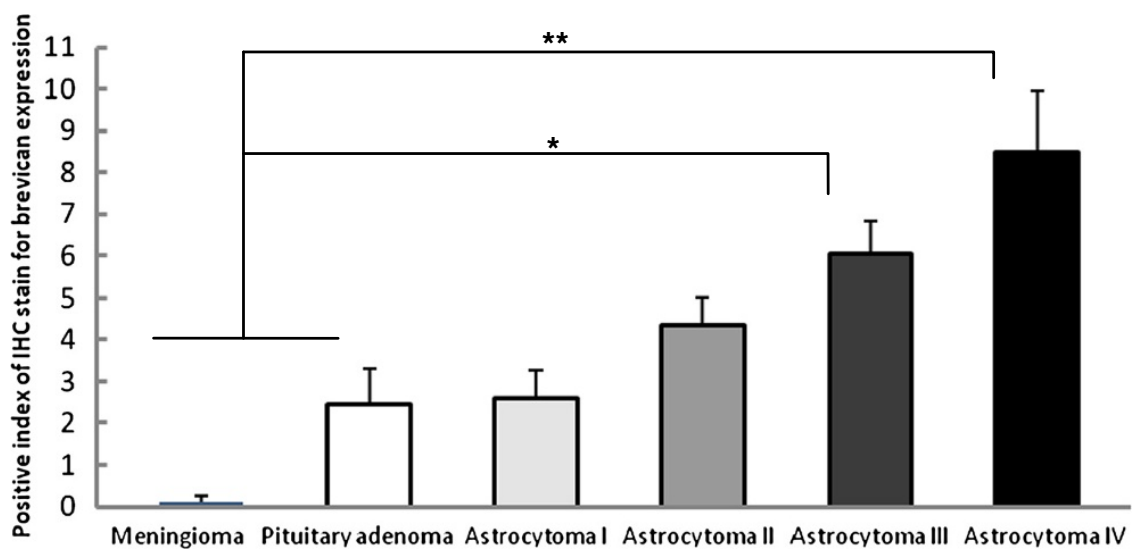

Figure 1 Brevican expression levels were detected by immunohistochemistry staining using an anti-brevican antibody. (A) The staining results were observed by microscopy. Meningioma was negative $(a$, blue; $n=20)$, pituitary adenoma was weakly-positive $(b$, light yellow; $n=20)$ and malignant glioma sections (astrocytoma grades I-IV, $n=15$ for each) were positive ( $c$ - $f$, yellow to brown; respectively). Hematoxylin was used for nuclear counterstaining (blue). Left: 100x, HE staining (above), IHC (lower); right: 400x, magnification of square frame sections in the left; (B) The immunohistochemistry PI of brevican expression in the gliomas (5.27 \pm 1.98$)$, especially for grade III and IV astrocytoma (6.07 \pm 2.30 and 8.07 \pm 2.22$)$, was significantly higher than that of benign brain tumors $(1.78 \pm 0.89) .{ }^{*}, P<0.05 ; * * P<0.01$.

was constructed using the scrambled shDNA sequence 5'-GATCCCCGCTCCTAGAATTTGAAACATTCAAG AGATGTTTCAAATTCTAGGAGCTTTTTGGAAA-3'. Stably transduced U251 cells that overexpress brevican were transfected with these plasmids for $24 \mathrm{~h}$ and then treated with $1.0 \mu \mathrm{g} / \mathrm{mL}$ puromycin. The remaining cells were cultured with $0.5 \mu \mathrm{g} / \mathrm{mL}$ puromycin until cell colonies formed, and Western blots were used to test for brevican levels.

\section{Cell adhesion and migration assays}

The stably transduced cells were resuspended in culture medium. A total of 50,000 suspended cells were added to a 96-well plate coated with human fibronectin $(20 \mu \mathrm{g} /$ $\mathrm{mL}$; Solarbio, Beijing) and poly-L-lysine $(50 \mu \mathrm{g} / \mathrm{mL}$; Sigma, St. Louis, MO). After an $1 \mathrm{~h}$ incubation, the plates were washed with PBS, fixed with $4 \%$ paraformaldehyde, and the $570 \mathrm{~nm}$ absorbance was quantified after crystal violet staining. For the migration assay, cells 
diluted in serum-free culture medium were plated onto 24-well plates preloaded with Transwell inserts $(8 \mu \mathrm{m}$ pore size; Costar, Cambridge, MA) at 50,000 cells per well in $100 \mu \mathrm{l}$ culture medium and allowed to migrate for $10 \mathrm{~h}$. Subsequently, the cells that had migrated to the underside were stained and counted using microscopy. All experiments were repeated at least three times.

\section{Cell proliferation, invasion and wound healing assays}

The transduced cells were plated on 24-well plates (1000 cells/well) and the cell colonies were counted at day 12 to measure the cell proliferation rate. For cell invasion experiments, Matrigel was plated inside Transwell culture inserts for $5 \mathrm{~h}$ at $37^{\circ} \mathrm{C}$ before cells were plated onto the inserts $(50,000$ cells/well). After $16 \mathrm{~h}$, the cells that migrated to the underside were stained and counted.

For the cell wound healing assays, a cell scraper was used to create scratch wound on a dish with cells grown to $80 \%$ confluence. The distances of the wounds were then measured using a microscope at 0,24 and $48 \mathrm{~h}$. Cell motility was evaluated using the following formula: cell motility $=\left(\right.$ distance $_{24 \mathrm{~h}}$ or $48 \mathrm{~h}-$ distance $\left._{0 \mathrm{~h}}\right) /$ distance $_{O h}$.

\section{Cytoimmunofluoresence staining}

Cells were grown on a slide chamber for $24 \mathrm{~h}$, fixed for $10 \mathrm{~min}$ in a cold mixture of methanol and acetone, and blocked with PBST containing $0.5 \%$ bovine serum albumin for $2 \mathrm{~h}$. Cells were incubated with anti-brevican polyclonal antibody $\mathrm{B} 5$ (1: 100) overnight at $4^{\circ} \mathrm{C}$, followed by incubation with $\mathrm{CF}^{\mathrm{TM}} 488 \mathrm{~A}$ labeled goat anti-

Table 2 Brevican expression and the clinicopathological characteristics of 60 patients with malignant glioma.

\begin{tabular}{lccc}
\hline Cases & $\begin{array}{c}\text { Brevican expression } \\
\text { positive cases (\%) }\end{array}$ & $\begin{array}{c}\text { Brevican expression } \\
\text { negative cases (\%) }\end{array}$ & P value \\
\hline Age & $25(78.1)$ & $7(21.9)$ & 0.10 \\
\hline$\leq 50$ & $16(57.1)$ & $12(42.9)$ & \\
\hline$>50$ & & & \\
\hline Gender & $22(73.3)$ & $11(36.7)$ & 0.58 \\
\hline Male & $19(63.3)$ & $9(60.0)$ & 0.01 \\
\hline Female & $6(40.0)$ & $6(40.0)$ & \\
\hline Histological grade & $3(20.0)$ & \\
\hline I & $9(60.0)$ & $1(6.7)$ & \\
\hline II & $12(80.0)$ & $15(50.0)$ & \\
\hline III & $14(93.3)$ & $4(13.3)$ & \\
\hline IV & $15(50.0)$ & & \\
\hline Degree of differentiation & & & \\
\hline Well & $26(86.7)$ & & \\
\hline Poorly & & & \\
\hline
\end{tabular}

rabbit secondary antibodies (Biotium, Hayward, CA) for $30 \mathrm{~min}$ at $37^{\circ} \mathrm{C}$. The cells were then observed under fluorescence microscopy.

\section{Western blot}

Whole cell lysates were used for immunoblotting as described previously [13]. Enhanced chemiluminescence detection was performed according to the manufacturer's instructions with an ECL kit (Thermo Scientific, Rockford, IL).

\section{Tumorigenicity analysis}

To validate the effects observed with brevican knockdown in vitro, BALB/c nude mice were injected subcutaneously into the right flank with either the $5 \times 10^{6} \mathrm{U} 251$ transduced cells, transduced U251/brevican-shDNA mock, or transduced U251/ brevican-shDNA 2. BALB/c nude mice (five mice per group) were purchased from the National Rodent Laboratory Animal Resources (Shanghai). Tumor measurements were made every 4 days and tumor sizes were calculated using the formula $\mathrm{V}=0.5 a^{\prime} \times b^{\prime 2}$, where $a^{\prime}$ and $b^{\prime}$ were the long and short diameters of the tumor. In addition, $2 \times 10^{5}$ cells were intracranially injected into the right thalamus of $\mathrm{BALB} / \mathrm{c}$ nude mice using a $10 \mu \mathrm{l}$ syringe. A total volume of $8 \mu \mathrm{l}$ cell suspension was injected at $2.5 \mathrm{~mm}$ anterior to the bregma and $2.0 \mathrm{~mm}$ lateral to the midline into three mice for each group. Magnetic resonance tomography (MRT) was used for comparing the orthotopic tumor growth in the nude mice.

\section{Statistical analysis}

A one-way ANOVA was performed using SPSS 13.0 software (SPSS Inc., Chicago, IL). The results were expressed as the means $\pm \mathrm{SD}$, and a $P$ value $<0.05$ was considered to be statistically significant.

\section{Results}

Brevican is differentially expressed in glioma and benign brain tumors

Immunohistochemical staining of 60 glioma tissue and 40 benign brain tumor samples showed that brevican was located and overexpressed in the extracellular matrix (ECM) and the cytoplasm of glioma cells, whereas the meningioma and pituitary adenoma samples were negative and weakly-positive, respectively. Diffuse positive staining for brevican was observed in glioma cells to varying degrees (Figure 1A $c-f$ ), compared with the benign tumor control group (Figure 1A $a, b$ ). The staining was especially diffuse and infiltrative for grade III and IV astrocytoma cells (Figure 1A $e, f$ ). The immunohistochemistry $P I$ of brevican expression in the gliomas $(5.27 \pm 1.03)$ was significantly higher than that of benign brain tumors (1.78 $\pm 0.86, P<0.05)$. 
Approximately $68.3 \%$ (41/60) of glioma samples showed positive staining $(P I>4.0)$, whereas only $22.5 \%$ (9/40) of the benign ones had positive staining, all of which were heterogeneously positive (9/20) pituitary adenoma cells (Figure 1B). In addition, the expression of brevican was not correlated with the age or sex of the patients (with $P$ values of 0.10 and 0.58 , respectively). However, the expression of brevican in patients with well-differentiated tumors was significantly higher than that of the patients with poorly differentiated tumors (anaplastic astrocytoma and glioblastoma) $(P=0.005$, Table 2).

\section{Brevican overexpression promoted cell adhesion and migration}

The glioma U251 and U87 cell lines do not express brevican in culture, probably due to the absence of microenvironment of tumor growth, i.e. specific inducing factors $[8,14]$. To overcome this limitation, we first generated pMX-mock- and pMX-brevican-stably- transfected 293T cells, U251 cells and U87 cells. Western blots revealed that pMX-brevican stably transduced 293T, U251 and U87 cells had much higher levels of brevican expression than control cells (Figure 2A).

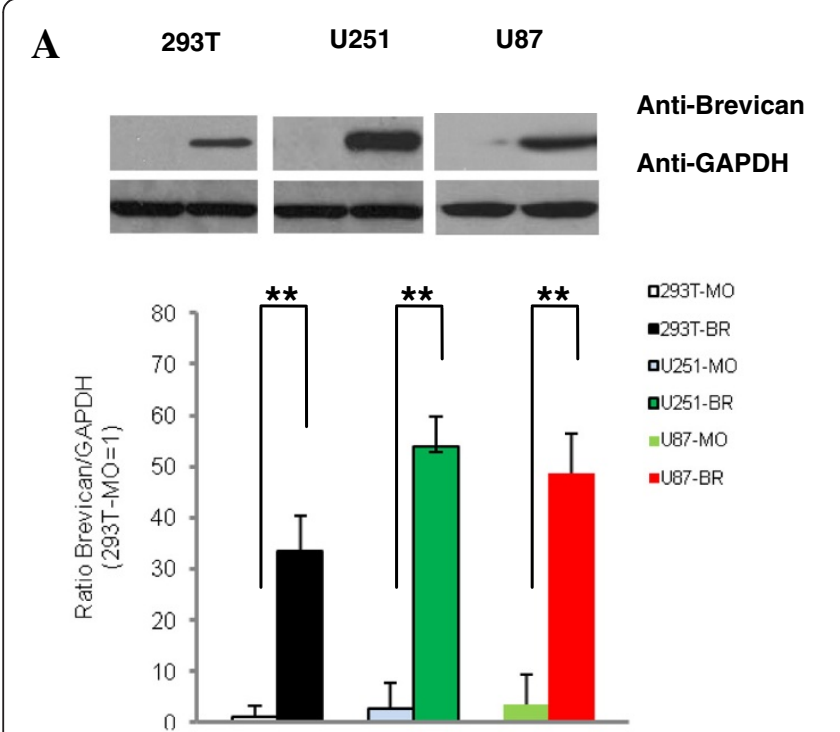

\section{B}

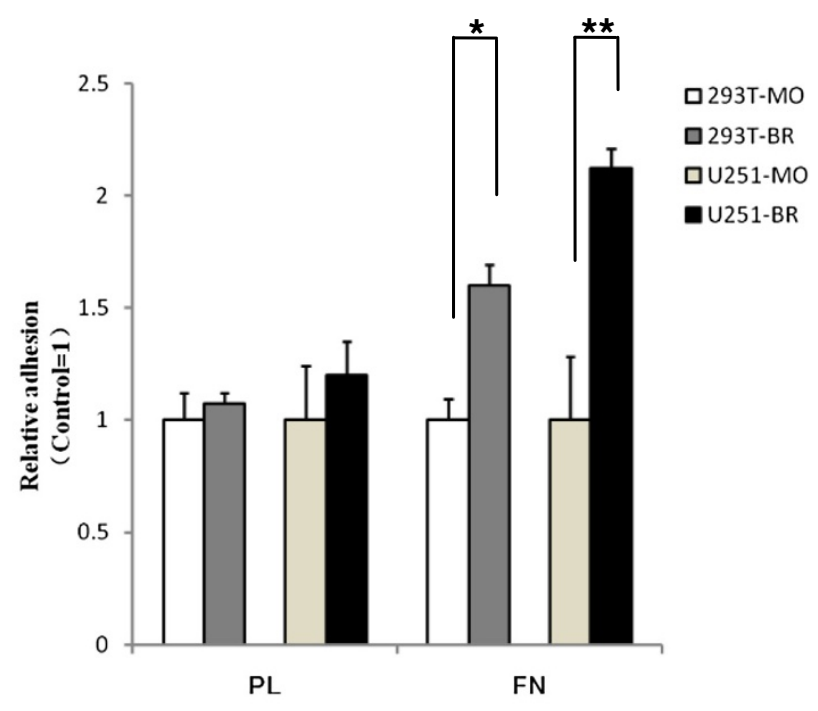

C
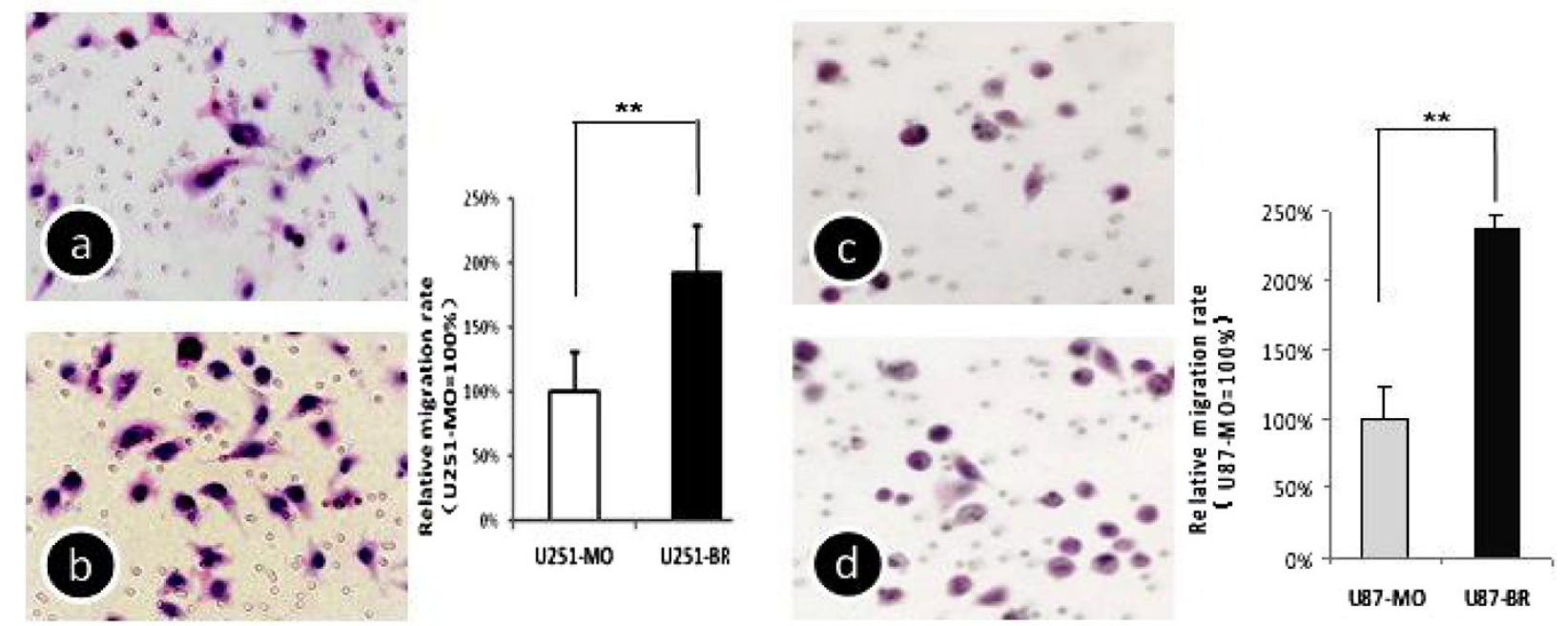

Figure 2 Brevican overexpression promoted cell adhesion and migration. (A) Brevican expression levels of stably transduced pMX-brevican cells were higher than those of control cells (B) Brevican expression enhanced fibronectin-dependent cell adhesion. PL, poly-L-lysine; FN, fibronectin. (C) Stably transduced U251 and U87 cells demonstrated migration through transwell inserts. Cells were stained with HE (200X), and the experiments were repeated at least three times; a: U251-MO; b: U251-BR; c: U87-MO; d: U87-BR; MO, the transduced cells with pMX-mock; $B R$, the transduced cells with $\mathrm{pMX}$-brevican. ${ }^{*} P<0.05 ; * P<0.01$. 
Therefore, these pMX-brevican stably transduced U251 cells, which were noted as "transduced U251 cells" were used for brevican overexpression experiments. Cell counting Kit-8 tests were used to ensure that the overexpression of brevican did not affect the proliferation of the transduced 293T, transduced U251, and transduced U87 cells (data not shown), as demonstrated previously by $\mathrm{Hu}$ et al. [15]. In cell adhesion and migration assays, the transduced cells generated traction and thereby migrated through the substrate. In this study, the results of the transwell assays showed that transfection with pMX-brevican significantly promoted the migration of
U251 and U87 cells (Figure 2B). Moreover, brevican expression enhanced the fibronectin-dependent cell adhesion (Figure 2C).

\section{Knockdown of brevican gene inhibited cell motility abilities}

We knocked-down the brevican expression successfully as revealed by Western blots (Figure 3A). Cell proliferation ability was significantly reduced in the transduced U251/brevican-shDNA 2 cells compared with the transduced U251 cells and the control cells by $85.8 \%$ and $83.6 \%$ at day 12 post plating, respectively (Figure $3 \mathrm{~B}$ ).
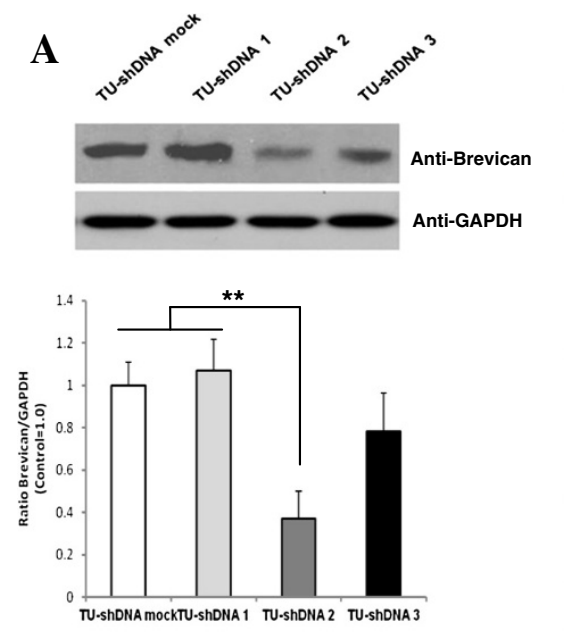

B

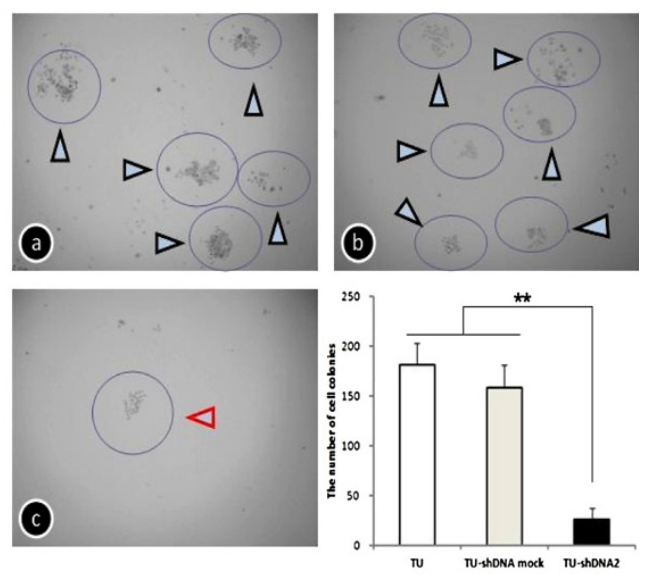

\section{C}
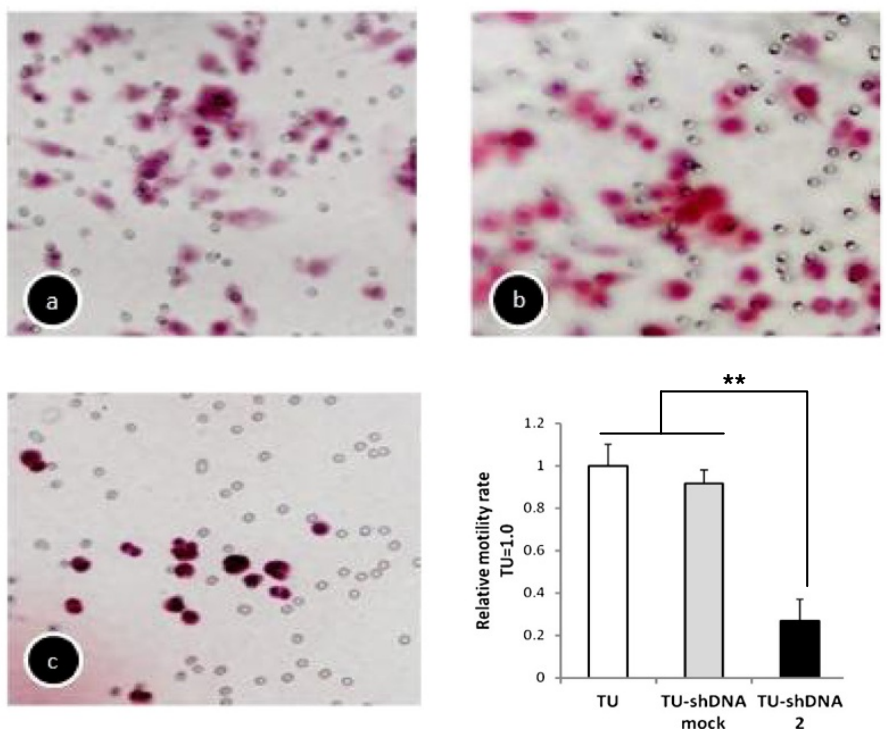

Figure 3 Brevican knockdown reduced glioma cell proliferation and invasion. (A) Brevican knockdown effectively down-regulated brevican expression. Western blot analysis of cell lysates demonstrated down-regulation of brevican protein in the transduced U251/brevican-shDNA 2 and the transduced U251/brevican-shDNA 3 cells by $52.3 \%$ and $23.4 \%$, respectively. (B) Optical microscopic observation showed that cell colony formation was inhibited in the transduced U251/brevican-shDNA 2 cells (c), compared with the transduced U251 cells (a) and the control cells (b). (C) The rate of cell invasion was also reduced in the transduced U251/brevican-shDNA 2 cells (c) compared with the transduced U251 cells (a) and control cells (b). TU, the transduced U251 cells (a); TU-shDNA mock, the transduced U251/brevican-shDNA mock cells (b); TU-shDNA2, the transduced U251/brevican- shDNA 2 cells (c). ${ }^{*} P<0.01$. 
Furthermore, the invasion abilities of the transduced U251/brevican-shDNA 2 cells through the Matrigel were dramatically decreased compared with the transduced U251 cells and the control cells by $73.3 \%$ and $64.7 \%$, respectively $(P<0.01$; Figure $3 C)$. These results confirmed that brevican plays an important role in glioma cell adhesion and migration.

The influence of brevican on cell migration was further observed in glioma cancer cells. The wound-healing results indicated that the migration ability of the transduced U251/brevican-shDNA 2 cells was also markedly decreased (Figure 4A). As shown in Figure 4B, cytoimmunofluoresence analyses showed cell infiltrating ability was inhibited and brevican expression was decreased. The spreading distance detected in the random migration assays was significantly reduced in brevican knockdown transfectants as compared with scrambled control cells.

\section{Brevican knockdown inhibits tumorigenicity in vivo}

At the fourth week post-inoculation, the growth of tumors formed by the transduced U251/brevicanshDNA 2 cells was significantly suppressed (Figure 5A). The xenograft transplants gave rise to much smaller tumors than those from control cells $(P<0.05)$. In addition, the brains of the nude mice injected intracranially were visualized with plain and Gd-DTPA-enhanced MRT at day 25. Similar to transduced gliomas created with another glioma cell line (CNS-1) [16,17], the transduced U251/brevican-shDNA mock transfected cell-

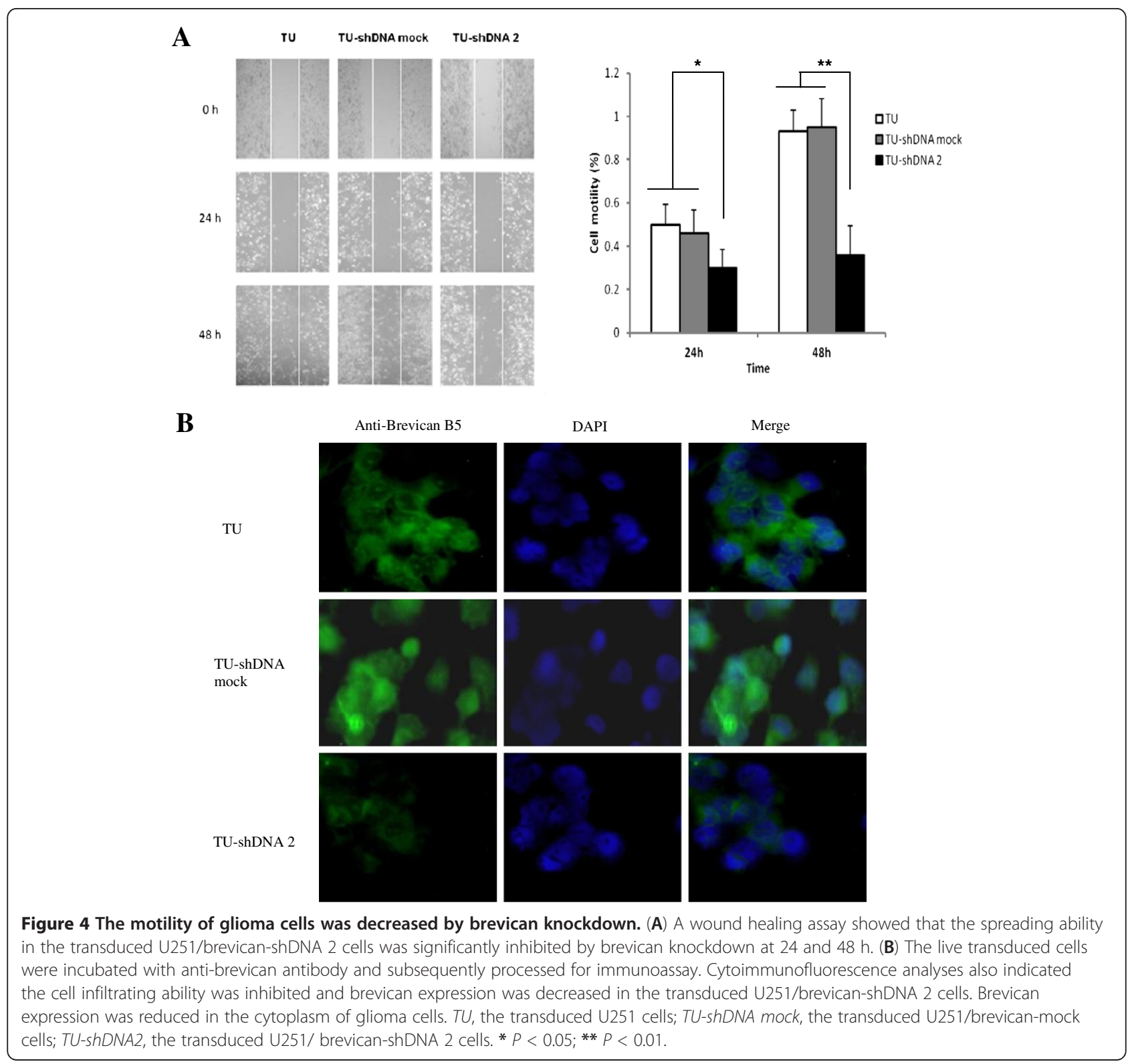


A
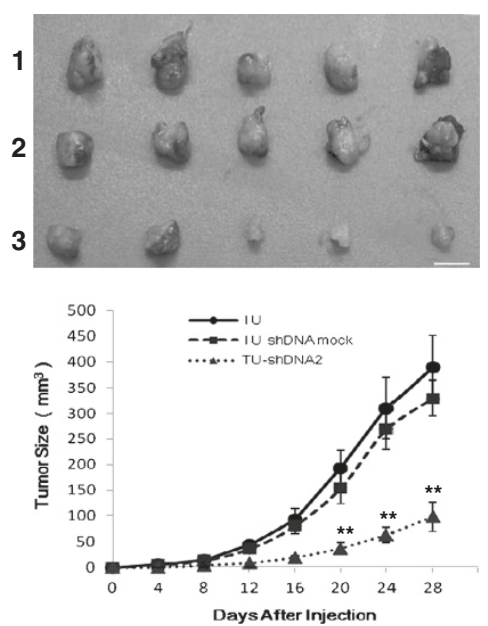

B
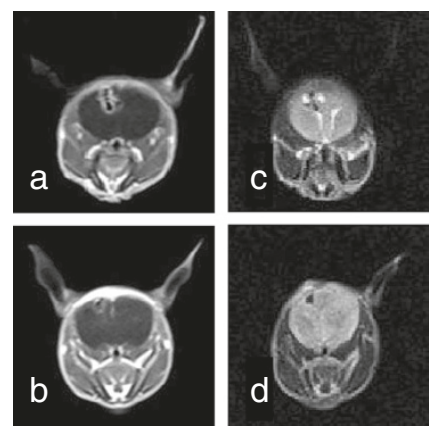

Figure 5 The tumorigenicity of the transduced U251/brevican-shDNA 2 cells was reduced in nude mice. (A) Photograph of subcutaneous tumors formed by the transduced U251 cells (1), the transduced U251/brevican-mock cells (2) and the transduced U251/ brevican-shDNA 2 cells (3) groups $(n=5)$ at day 28. Bars are $10 \mathrm{~mm}$. (B) The plain MRT and Gd-DTPA-enhanced MRT results for brain sections showed that the tumorigenicity of the transduced U251/brevican-shDNA 2 cells $(b, d)$ was dramatically limited at day 25 ( $n=3)$, compared with the transduced U251/brevican-shDNA mock cells ( $a$, c). Also, the diffusion degree of the transduced U251/brevican-mock cells $(a, c)$ was more extensive than the transduced U251/brevican-shDNA 2 cells' $(b, d)$. TU, the transduced U251 cells; TU-shDNA mock, the transduced U251/brevican-mock cells; TU-shDNA2, transduced U251/brevican-shDNA 2 cells; $a$, $b$, the plain MRT results; $c$, $d$, Gd-DTPA-enhanced MRT results. * $P<0.05 ; * * P<0.01$.

derived gliomas were invasive and exhibited cell clusters that detached from the tumor core (Figure $5 \mathrm{~B} a, c$ ), as well as extensive diffusion of single cells within the brain parenchyma. However, transduced U251/brevicanshDNA 2 cells produced smaller (Figure 5B $b, d$ ), less diffuse and less infiltrative tumors than that of the control transduced U251/brevican-shDNA mock cell tumors (volumes: $3.6 \pm 1.5 \mathrm{~mm}^{3}$ versus $10.3 \pm 2.6 \mathrm{~mm}^{3} ; \mathrm{n}=3$, respectively; $P<0.01$ ).

\section{Discussion}

The ECM has an active role in regulating the activity and behavior of cells, including cell shape, differentiation, proliferation and cell death. In recent studies, the nervous ECM (NECM) was re-evaluated. To date, several studies showed that the solubility of the NECM increased in glioma, which might be related to the upregulation of brevican [18-21].

In this study, we first explored the physiological role of brevican by investigating its spatiotemporal expression by IHC. Brevican was abundantly expressed in glioma tissues, particularly in grade III and grade IV astrocytomas, whereas brevican only expressed weakly in pituitary adenoma tumor tissue and negative in meningioma tissue. These data suggest that brevican is produced by astrocytoma cells, before being secreted and bound to the cellular cytoplasm and ECM. In the transduced brevican-expressing U251 cells, brevican was also detected on the surface of these cells using cytoimmunofluorescence. The expression of a tumor-specific brevican found in all high-grade gliomas suggested that it might play a significant role in glioma progression. Moreover, previous studies have shown that brevican is expressed at relatively low levels in normal adult brain $[10,22]$. Therefore, the absence or down-regulation of brevican in benign gliomas prompts its use as a differentiation marker to distinguish primary brain tumors with similar histology, but with a different pathologic course.

Here, we established an in vitro model to reproduce the motogenic effects of brevican. Our results indicated that brevican can promote cell adhesion and was essential for the migration of U251 cells. Brevican may interact with fibronectin (FN) to act as a motogenic signal. FN interacts with multiple cell surface receptors and plays an important role in the regulation of anchoragedependent cell growth, cell migration, tumor development and metastasis. Cell adhesion to immobilized FN leads to the assembly of focal adhesions, which require the small GTPase Rho and then affect many cellular functions, such as cell motility, differentiation, matrix assembly, and cell cycle progression [23]. A combination of brevican cytological mechanisms and the particular composition of the neural microenvironment may underlie this unique ability of glioma to disperse in the CNS. In addition, it has been demonstrated that secreted brevican isoforms have evolved to become the predominant brevicans in the adult brain [24]. Our studies suggested that brevican overexpression in glioma is associated with cancer progression, and therefore, brevican might be a useful biomarker of glioma. 
Furthermore, we also generated brevican knockdown transduced U251 cells using loss-of function techniques. We found that brevican knockdown affected cell invasion and might explain how endogenous brevican exerts its effects on cell adhesion. We confirmed that brevican can promote glioma cell adhesion [15,25]. Moreover, a distinct inhibition of the spreading and expression of brevican was observed surrounding the core of suppressed transduced U251 cells using a cytoimmunofluorescence assay. At this point we speculate that mechanisms that recycle adhesion receptors via endosomal compartments may contribute to migration. Results from our wound-healing experiments confirm this hypothesis.

Gliomas are highly invasive [26]. The ability of tumor cells to interact with the components of the NECM affects numerous cellular processes, and inappropriate expression of these matrix components has been associated with glioma invasion and growth $[8,14]$. One NECM component that has been implicated in glioma biology is brevican, and increasing studies have focused on brevican and mechanisms of glioma invasion in recent years [27]. Brevican's involvement in glioma invasion may explain why many physiological processes require closely regulated degradation of the NECM [28].

In light of the effects of brevican on cell motility, we investigated the tumorigenicity of differential brevican expression in vivo. To date, little is known of the molecular basis that allows glioma cells to overcome the barriers that inhibit motility in the adult nervous tissue [29-31]. In this study, we found that brevican was highly overexpressed in glioma and distinctively promoted cell adhesion ability. The change of the NECM in the nervous system is critical for tumor cell aggression and invasion. To overcome the barriers to cell motility, glioma cells degrade the NECM and secrete their own matrix components. Our work demonstrated that the xenograft transplants using brevican knockdown cells gave rise to much smaller tumors, and had less diffuse and less infiltrative tumors than those of control groups. Overall, the deposition of brevican into the NECM may disrupt matrix processing and alter extracellular molecular events that modulate neural solubility.

\section{Conclusions}

This study indicates that the expression of brevican is associated with glioma cell adhesion, motility and tumor growth. Brevican also plays an important role in glioma progression, and therefore, may be a useful marker of glioma.

\footnotetext{
Abbreviations

FN: Fibronectin; CNS: Central nervous system; PGs: Proteoglycans;

CSF: Cerebrospinal fluid; IHC: Immunohistochemical staining;
}

HE: Hematoxylin and eosin; PI: Positive index; shDNA: Short hairpin DNA; ECM: Extracellular matrix; NECM: Nervous extracellular matrix.

\section{Competing interests}

The authors declare that they have no competing interests.

\section{Authors' contributions}

RQL constructed the recombinant plasmids, detected brevican expression levels in the transduced cells, measured cell adhesion and invasion and drafted the manuscript. YCL, LG and WM collected all the tissue samples and analyzed the expression levels of brevican. CSW prepared the anti-brevican antibody and performed the immunohistochemical staining. HJW and JBD performed the in vivo experiments, ETW reviewed the manuscript, MY conceived and supervised the project, and reviewed the manuscript. All authors have read and approved the final manuscript.

\section{Acknowledgment}

This work was supported by grants from the National Natural Science Foundation of China (project number: 30870565 and 81171912).

\section{Author details}

'Department of Biochemistry and Molecular Biology and the Key Laboratory of Molecular Medicine, Ministry of Education, Shanghai 200032, China. ${ }^{2}$ Department of Clinical Laboratory, Fudan University Shanghai Cancer Center, Shanghai, China. ${ }^{3}$ Department of Neurosurgery, Provincial hospital affiliated to Shandong University, Jinan, China. ${ }^{4}$ Department of Clinical Oncology, Fudan University Shanghai Cancer Center, Shanghai, China. ${ }^{5}$ Gamma Knife Center, Huashan Hospital, Shanghai, China. ${ }^{6}$ Brain Tumor Center and Neuro-Oncology Unit, Department of Neurology, Beth Israel Deaconess Medical Center, Harvard Medical School, Boston, MA, USA.

Received: 9 October 2012 Accepted: 11 December 2012

Published: 19 December 2012

\section{References}

1. Bolteus AJ, Berens ME, Pilkington GJ: Migration and invasion in brain neoplasms. Curr Neurol Neurosci Rep 2001, 1(3):225-232.

2. Norden AD, Young GS, Setayesh K, Muzikansky A, Klufas R, Ross GL, Ciampa $A S$, Ebbeling LG, Levy B, Drappatz J, et al: Bevacizumab for recurrent malignant gliomas: efficacy, toxicity, and patterns of recurrence. Neurology 2008, 70(10):779-787.

3. Iwamoto FM, Abrey LE, Beal K, Gutin PH, Rosenblum MK, Reuter VE, DeAngelis LM, Lassman AB: Patterns of relapse and prognosis after bevacizumab failure in recurrent glioblastoma. Neurology 2009, 73(15):1200-1206.

4. Rauch U, Meyer $H$, Brakebusch C, Seidenbecher C, Gundelfinger ED, Beier $D R$, Fassler R: Sequence and chromosomal localization of the mouse brevican gene. Genomics 1997, 44(1):15-21.

5. Ruoslahti E: Brain extracellular matrix. Glycobiology 1996, 6(5):489-492

6. Yamaguchi Y: Lecticans: organizers of the brain extracellular matrix. Cell Mol Life Sci 2000, 57(2):276-289.

7. Gary SC, Zerillo CA, Chiang VL, Gaw JU, Gray G, Hockfield S: cDNA cloning, chromosomal localization, and expression analysis of human BEHAB/brevican, a brain specific proteoglycan regulated during cortical development and in glioma. Gene 2000, 256(1-2):139-147.

8. Jaworski DM, Kelly GM, Piepmeier JM, Hockfield S: BEHAB (brain enriched hyaluronan binding) is expressed in surgical samples of glioma and in intracranial grafts of invasive glioma cell lines. Cancer Res 1996, 56(10):2293-2298.

9. Zhang H, Kelly G, Zerillo C, Jaworski DM, Hockfield S: Expression of a cleaved brain-specific extracellular matrix protein mediates glioma cell invasion In vivo. J Neurosci 1998, 18(7):2370-2376.

10. Viapiano MS, Bi WL, Piepmeier J, Hockfield S, Matthews RT: Novel tumorspecific isoforms of $B E H A B /$ brevican identified in human malignant gliomas. Cancer Res 2005, 65(15):6726-6733.

11. Lu R, Sun M, Feng J, Gao X, Guo L: Myofibrillogenesis regulator 1 (MR-1) is a novel biomarker and potential therapeutic target for human ovarian cancer. BMC Cancer 2011, 11:270. 
12. Choudhury KR, Yagle KJ, Swanson PE, Krohn KA, Rajendran JG: A Robust Automated Measure of Average Antibody Staining in Immunohistochemistry Images. J Histochem Cytochem 2010, 58(2):95-107.

13. LU RQ Wu HJ, Guo L: Construction, Expression of HE4 Fusion Protein and its identification. Chin J Lab Diag 2010, 14:17-19.

14. Nutt CL, Matthews RT, Hockfield S: Glial tumor invasion: a role for the upregulation and cleavage of BEHAB/brevican. Neuroscientist 2001, 7(2):113-122.

15. Hu B, Kong LL, Matthews RT, Viapiano MS: The proteoglycan brevican binds to fibronectin after proteolytic cleavage and promotes glioma cell motility. J Biol Chem 2008, 283(36):24848-24859.

16. Viapiano MS, Hockfield S, Matthews RT: BEHAB/brevican requires ADAMTS-mediated proteolytic cleavage to promote glioma invasion. J Neurooncol 2008, 88(3):261-272.

17. Candolfi M, Curtin JF, Nichols WS, Muhammad AG, King GD, Pluhar GE, McNiel EA, Ohlfest JR, Freese AB, Moore PF, et al: Intracranial glioblastoma models in preclinical neuro-oncology: neuropathological characterization and tumor progression. J Neurooncol 2007, 85(2):133-148.

18. Goldbrunner RH, Bernstein JJ, Tonn JC: Cell-extracellular matrix interaction in glioma invasion. Acta Neurochir (Wien) 1999, 141(3):295-305. discussion 304-295.

19. Jaworski DM, Kelly GM, Hockfield S: BEHAB, a new member of the proteoglycan tandem repeat family of hyaluronan-binding proteins that is restricted to the brain. J Cell Biol 1994, 125(2):495-509.

20. Seidenbecher Cl, Richter K, Rauch U, Fassler R, Garner CC, Gundelfinger ED: Brevican, a chondroitin sulfate proteoglycan of rat brain, occurs as secreted and cell surface glycosylphosphatidylinositol-anchored isoforms. J Biol Chem 1995, 270(45):27206-27212.

21. Yamada H, Watanabe K, Shimonaka M, Yamaguchi Y: Molecular cloning of brevican, a novel brain proteoglycan of the aggrecan/versican family. J Biol Chem 1994, 269(13):10119-10126.

22. Viapiano MS, Matthews RT, Hockfield S: A novel membrane-associated glycovariant of $\mathrm{BEHAB} / \mathrm{brevican}$ is up-regulated during rat brain development and in a rat model of invasive glioma. J Biol Chem 2003, 278(35):33239-33247.

23. Wang R, Clark RA, Mosher DF, Ren XD: Fibronectin's central cell-binding domain supports focal adhesion formation and Rho signal transduction. J Biol Chem 2005, 280(31):28803-28810.

24. Yamaguchi Y: Brevican: a major proteoglycan in adult brain. Perspect Dev Neurobiol 1996, 3(4):307-317.

25. Lettau I, Hattermann K, Held-Feindt J, Brauer R, Sedlacek R, Mentlein R: Matrix metalloproteinase-19 is highly expressed in astroglial tumors and promotes invasion of glioma cells. J Neuropathol Exp Neurol 2010, 69(3):215-223

26. Louis DN: Molecular pathology of malignant gliomas. Annu Rev Pathol 2006, 1:97-117.

27. Nutt CL, Zerillo CA, Kelly GM, Hockfield S: Brain enriched hyaluronan binding (BEHAB)/brevican increases aggressiveness of CNS-1 gliomas in Lewis rats. Cancer Res 2001, 61(19):7056-7059.

28. Stanton $\mathrm{H}$, Melrose J, Little CB, Fosang AJ: Proteoglycan degradation by the ADAMTS family of proteinases. Biochim Biophys Acta 1812, 12:1616-1629.

29. Pilkington GJ: The paradox of neoplastic glial cell invasion of the brain and apparent metastatic failure. Anticancer Res 1997, 17(6B):4103-4105.

30. Subramanian A, Harris A, Piggott K, Shieff C, Bradford R: Metastasis to and from the central nervous system-the 'relatively protected site'. Lancet Oncol 2002, 3(8):498-507.

31. Cattaruzza S, Perris R: Proteoglycan control of cell movement during would healing and cancer spreading. Matrix Biol 2005, 24(6):400-417.

doi:10.1186/1471-2407-12-607

Cite this article as: Lu et al.: The role of brevican in glioma: promoting tumor cell motility in vitro and in vivo. BMC Cancer 2012 12:607.

\section{Submit your next manuscript to BioMed Central and take full advantage of:}

- Convenient online submission

- Thorough peer review

- No space constraints or color figure charges

- Immediate publication on acceptance

- Inclusion in PubMed, CAS, Scopus and Google Scholar

- Research which is freely available for redistribution

Submit your manuscript at www.biomedcentral.com/submit 